Editorial

\title{
COVID-19, Infodemia y un Buen Café
}

\author{
COVID-19, Infodemia, and a Good Coffee
}

\author{
Juan Aníbal González Rivera ${ }^{1 *}$, \& Yazmín Álvarez-Alatorre ${ }^{2}$ \\ 1 Fundación para el Desarrollo de la Psicología en el Caribe. (D) https://orcid.org/0000-0003-0622-8308 \\ 2 Fundación para el Desarrollo de la Psicología en el Caribe. (ID https://orcid.org/0000-0001-8989-1679 \\ * Correspondencia: jagonzalez@psm.edu
}

WWW.REVISTACARIBENADEPSICOLOGIA.COM

\author{
Citar como: \\ González-Rivera, J. A., \& Álvarez-Alatorre, Y. (2020). COVID-19, infodemia y un buen café. Revista Caribeña de \\ Psicología, 4(2), 81-87. https://doi.org/10.37226/rcp.v4i2.4901
}

\section{Editorial Volumen 4, Número 2, 2020}

La sobreabundancia y exposición a la información, difundida a gran escala por los diferentes medios de comunicación y artefactos tecnológicos, es una de las características que marcó los inicios del siglo XXI. Esto provocó que surgieran conceptos para describir un nuevo mal social, que ha permanecido y se ha intensificado con el paso de los años. Así pues, BenitoRuiz (2009) introduce el término "infoxicación", en alusión a la saturación o intoxicación informacional generada por el cúmulo excesivo de datos que provoca una visión confusa, ininteligible y opaca de la realidad. Esto es paradójico pero representativo de nuestra realidad social actual ya que, aun teniendo un mayor acceso a la información, la capacidad de procesamiento de la mente humana es sobrepasada por el exceso de información, afectando la comprensión de los acontecimientos (Area-Moreira \& Pessoa, 2012). De este modo, se hace imperiosa la creación de nuevas estrategias para hacer frente a esta avalancha de información y examinar la brecha entre ésta y la capacidad humana (Fraser \& Dunstan, 2010). En respuesta a esta problemática, algunos autores han creado interesantes modelos de desinfoxicación que han surgido de la necesidad de reducir el exceso de información (Baquero et al., 2017).

La segunda década del siglo XXI se ha distinguido por apresurados cambios en las formas en que se transmite, produce y disemina la información, gene- rando innovadores elementos creativos basados en el fortalecimiento del trabajo en red y una marcada tendencia a la inter y transdisciplinariedad (Alfonso \& Fernández, 2020). La red de redes, Internet, no es solo un conjunto de cables y herramientas tecnológicas que facilitan la comunicación mundial, es sobre todo un punto de encuentro entre seres humanos que comparten intereses, problemáticas o afectos. Las redes sociales, por ejemplo, tienen una dualidad en su potencial. Por un lado, incitan al ocio y la comunicación informal, y por otro, a la formación profesional y el aprendizaje. Esto provoca manifestaciones divergentes, ya que por una parte generan fenómenos de movilización política como revoluciones o reclamos civiles (por ejemplo, la protesta masiva del 25 de julio del 2019 en Puerto Rico donde se exigía la renuncia del entonces gobernador Ricardo Roselló) y por otra, se observan comportamientos con cierta tendencia al exhibicionismo, principalmente en los jóvenes al compartir opiniones, fotos, imágenes, entre "amigos" en plataformas como Facebook o Twitter (Area-Moreira \& Pessoa, 2012).

Actualmente, el COVID-19 lidera las noticias, que se difunden por nuestras redes sociales agitando a la sociedad. Las escuelas cerraron y aún no se sabe cuándo reabrirán, se cancelaron exámenes y graduaciones, las fiestas ahora son en línea; el mundo cambió. La respuesta pública a esta pandemia varía. La 
ansiedad en estos casos es esperada, incluso, dosis adecuadas de ansiedad pueden ser útiles, ya que nos harían tomar en serio las recomendaciones de aislamiento o distancia social, entre otras medidas de prevención. Pero también ha habido cierto pánico social, tan contagioso y peligroso como el COVID-19. Este puede hacer que los humanos, como grupo, sean irracionales o egoístas (McCartney, 2020). Según declaraciones de la Organización Mundial de la Salud (OMS), el brote de COVID-19 llegó acompañado de una "infodemia masiva", es decir, una cantidad excesiva de información que bien puede ser cierta o no, y que dificulta encontrar fuentes fidedignas (Organización Panamericana de la Salud [OPS], 2020). El término infodemia se relaciona al aumento de volumen de información respecto a un tema particular, que ante eventos como la actual pandemia se puede volver exponencial. En la era de la información, este fenómeno se magnifica y se propaga con igual o mayor rapidez que un virus (Zarocostas, 2020).

La divulgación de información deliberadamente falsa se ha convertido en un problema sanitario, que ha visto sus efectos desde epidemias pasadas como la del virus del Ébola en el 2014 y en asuntos como el rechazo de las vacunas (Salaverría et al., 2020). La ciencia médica se afecta significativamente con la desinformación del COVID-19 pues crea confusión que causa impacto inmediato en el mundo y la sociedad en general; es más tóxica y más mortal que la desinformación sobre otros asuntos (Posetti \& Bontcheva, 2020). Sin embargo, ningún precedente se compara con el inédito escenario que se vive ante la pandemia del COVID-19, donde la proliferación de información manipulada, teorías conspiratorias y contenidos descontextualizados, se multiplican incontrolablemente (Salaverría et al., 2020). Por ejemplo, un rumor infundado que se ha propagado con gran rapidez es que el virus fue creado por los gobiernos de China o Estados Unidos (Fischer \& Fried, 2020).

En el mes de marzo, según un estudio de la Universidad de Illinois, se enviaron 550 millones de "tuits" que incluían palabras relacionadas a pandemia y coronavirus; los mismos provenían en su mayoría de Estados Unidos (OPS, 2020). Por otra parte, entre el 24 y el 27 de enero, cerca de 13,000 mensajes publicados entre las plataformas de Twitter, Facebook y Reddit contenían información relacionada a teorías de cons-piración indicando que el virus podría ser un arma biológica o un método despoblacional (Fischer \& Fried, 2020). Las principales compañías de redes sociales virtuales como, Facebook, YouTube y Google, tienen la presión de combatir el esparcimiento de desinformación acerca del COVID19 en sus plataformas. Twitter anunció la implementación de etiquetas con mensajes de alerta ante algunos tuits con información dudosa acerca del COVID19, y eventualmente extenderá esa medida a otros temas (Culiford, 2020). Del 14 de marzo al 13 de abril del 2020, durante el estado de alarma por la pandemia de COVID-19, se realizó un estudio en España, que reflejó que las aplicaciones móviles de mensajería o redes sociales cerradas son donde se diseminan en mayor grado y con mayor peligrosidad los contenidos deliberadamente falsos, siendo WhatsApp la plataforma de mayor cantidad y alcance (Salaverría et al., 2020).

Otros ejemplos de noticias falsas que han circulado por las redes y que han recorrido el mundo (y en muchas ocasiones, se han puesto en práctica) son el bañarse con agua caliente para prevenir la infección, creer que el virus no puede transmitirse en climas cálidos y que helicópteros de la fuerza aérea pulverizarán desinfectante para erradicar el virus (Alfonso \& Fernández, 2020). En la cotidianidad de los hogares de todo el mundo corren rumores con curas y remedios caseros para combatir o prevenir la infección, pero estas se aproximan más a un placebo. La Agencia France-Presse (AFP) identificó algunos de estos mitos y remedios para desmitificarlos y estar alertas a prácticas no probadas científicamente, entre ellos están: aguantar la respiración y beber sorbos de agua para evitar el contagio, beber mucha agua con limón o tomar vitamina C para prevenirlo, el "antídoto" de Nicolás Maduro como cura del virus, hacer gárgaras con sal para matar el coronavirus, entre otros, como consumir ciertos alimentos y tés para combatirlo (López \& Pérez, 2020). Es por esto, que la UNESCO creó un documento con un resumen de políticas a implementar tomando como base el título "Desinfodemia", término que va en contra de la desinformación y a favor de información verificable, confiable, producto del desarrollo de la ciencia y el periodismo profesional (Posetti \& Bontcheva, 2020). Además, el documento hace énfasis en la necesidad de promover la alfabetización mediática e informacional a través del 
pensa-miento crítico y la verificación de contenidos digitales (Alfonso \& Fernández, 2020).

Hasta ahora, hemos expuesto diferentes términos en materia de información y sus efectos durante la pandemia por COVID-19. Sin embargo, hay que aclarar que muchos de ellos en sus definiciones pueden solaparse, por lo que hay que diferenciarlos. Por ejemplo, un término muy empleado tanto en el ámbito de la investigación como en organismos políticos internacionales es "Fake News", sin embargo, hay organizaciones como la Comisión Europea y la UNESCO que prefieren un término más general, y optan por el de "Desórdenes de Información" (Ireton \& Posetti, 2018). Estos desórdenes incluyen tres conceptos principales: 1) información errónea, que es información falsa pero la persona que la difunde la cree cierta, 2) desinformación, es información falsa que la persona transmite sabiéndolo y difunde la mentira deliberada e intencionalmente, y 3) mala información, es información basada en la realidad pero que se difunde con la mala intención de hacer daño a una persona, organización o país (Ireton \& Posetti, 2018). Salaverría et al. (2020) añaden en un estudio reciente, el término "bulo", como parte de los desórdenes de información y lo definen como "todo contenido intencionadamente falso y de apariencia verdadera, concebido con el fin de engañar a la ciudadanía, y difundido públicamente por cualquier plataforma o medio de comunicación social". Ese estudio identificó cuatro tipos de bulos que se difunden mayormente durante la pandemia por COVID-19: bromas, exageraciones, descontextualizaciones y engaños (Salaverría et al., 2020). El bulo "broma" lo definen como el tipo de bulo que consiste en la difusión de información falsa, con un fin burlesco, paródico, satírico o caricaturesco. Estos no deben ser tomados a la ligera pues las consecuencias de su difusión pueden ser devastadoras, principalmente si vienen de la voz de figuras de poder, como veremos a continuación.

En el momento más crítico de la pandemia del COVID-19 en Estados Unidos (23 de abril de 2020), Donald Trump, el presidente de los Estados Unidos, dio las siguientes recomendaciones "sarcásticas" como medidas preventivas y combativas ante el COVID-19: 1) introducir una luz ultravioleta en el cuerpo y 2) inyectarse desinfectante en el cuerpo. Las consecuencias de dichas declaraciones exageradas, descontextualizadas, satíricas y burlescas, tuvieron consecuen- cias, pues al día siguiente se reportaron cientos de casos con intentos, o indagaciones acerca de la opción de inyectarse desinfectante. Así como hubo personas que reaccionaron ante las imprudentes recomendaciones de Trump, otros pueden apoyarse en otro tipo de conductas para lidiar con sus problemas, como por ejemplo con el uso de sustancias psicoactivas (alcohol, nicotina, cannabis, etc.) y caer en medidas de afrontamiento conocidas como "automedicación emocional" (Khantzian, 1997). Aunque la automedicación no es en esencia un mal comportamiento, en la actual crisis pandémica se debe evitar y se considera una mala decisión. Por lo tanto, en esta difícil situación de emergencia que se vive a nivel mundial, no debemos olvidar que el encierro forzado facilita la emergencia de cuadros de estrés, ansiedad y depresión (López \& Pérez, 2020) y que controlar la información a la que estamos expuestos debe ser incluida dentro de las medidas de prevención y cuidado de la salud.

Consecuencias Psicológicas de la Cuarentena por COVID-19 y su Relación con los Desórdenes de Información

El Centro de Control y Prevención de Enfermedades (CDC, por sus siglas en inglés, 2020) indica el uso correcto de los términos cuarentena y aislamiento, que en estos tiempos de pandemia es común que se utilicen indistintamente, por lo que es importante diferenciarlos. La cuarentena se usa para mantener a alguien que podría haber estado expuesto al COVID-19 lejos de los demás; esto ayuda a prevenir la propagación del virus que puede ocurrir antes de que la persona sepa que está contagiada o que aún no manifiesta síntomas. Por otro lado, el aislamiento se usa para separar a las personas infectadas con el virus de aquellas que no lo están; deben permanecer en sus hogares o en un cuarto o área específica, separados de los demás hasta que sea seguro volver a tener contacto con otros. Ambos términos implican la separación como medida de protección, por lo que pueden confundirse.

El brote de este virus ha puesto a ciudades enteras en cuarentena alrededor del mundo. Estas medidas tienen precedentes, como las cuarentenas impuestas en áreas de China y Canadá durante el brote del Síndrome Respiratorio Agudo (SARS) en el 2003 o aldeas enteras de varios países de África occidental durante 
el virus del Ébola en el 2014. La cuarentena suele ser una experiencia desagradable para quienes la padecen debido a la separación de los seres queridos, la pérdida de libertad, la incertidumbre sobre el estado de la enfermedad y el aburrimiento, que en ocasiones pueden tener efectos dramáticos (Brooks et al., 2020). Lorenzo et al. (2020) indican que el comportamiento humano ante la cuarentena obligatoria se asocia a la imperiosa necesidad de mantener y respetar el distanciamiento exigido por las autoridades. Además, añaden que es esperado que se produzcan efectos psicológicos negativos como el estrés agudo, confusión, agresividad y violencia, entre otros. También, ante la prolongación indefinida de la cuarentena, puede incrementar el temor hacia la enfermedad, el aburrimiento, el estrés debido a pérdidas y prevalecerán manifestaciones emocionales como el miedo, la frustración, el enojo, ambivalencia, desorganización, tristeza, soledad y ansiedad (Lorenzo et al., 2020).

En una extensa revisión de literatura realizada por Brooks et al. (2020) para estudiar el impacto psicológico que tiene la cuarentena en las personas, encontraron la presencia de efectos psicológicos negativos, incluidos síntomas de estrés postraumático, confusión y enojo. Identificaron, además, como factores estresantes una mayor duración de la cuarentena, temores de infección, frustración, aburrimiento, suministros inadecuados, información inadecuada, pérdidas financieras y estigma; algunos de estos efectos pueden ser duraderos. Es probable que el miedo induzca comportamientos impulsivos de rechazo o discriminación de personas, e incluso imaginar fuentes de peligro irreales o eventuales competidores por determinados productos de higiene. Es por esto, que debe imperar la empatía cuando todos atravesamos por la misma situación; se debe evitar competir y discriminar, y a su vez promover el compartir y el colaborar pues la situación en la que vivimos es comunitaria. La solidaridad entre ciudadanos es vital; hay cambiar esa visión negativa de ver al otro como enemigo pues ante situaciones de emergencia como la que vivimos, pudiera convertirse en nuestro único auxilio y aliado (Gallegos et al., 2020).

Hay noticias que, aún proviniendo de fuentes confiables, resultan abrumadoras. Por ejemplo, saber que la enfermedad infecciosa COVID-19 es un cuadro respiratorio altamente contagioso y potencialmente letal, que a pocas semanas después de haber sido decla- rado pandemia por la OMS (el 11 de marzo del 2020), ya había más de 200 mil muertos y más de 3 millones de contagiados (López \& Pérez, 2020). Si a eso añadimos, que hasta el momento no hay cura ni vacuna para combatirlo o prevenirlo, el panorama se torna aún más desalentador. Además, el personal de apoyo en el área de salud también está en riesgo, y sabemos que servicios de enfermería, médicos, profesionales en salud mental y de servicios sociales, están cada vez más expuestos. Hay temor de que en las instituciones de salud no se cuente con el mejor equipo para garantizar la protección de aquellos que atienden a los pacientes en primera línea. Los informes de profesionales de la salud que mueren en otros países son crudos. Las pandemias mundiales nos llegan a todos, y como especie, parece que estamos un poco aturdidos por nuestra falta de autonomía sobre esta pandemia (McCartney, 2020).

Vivimos en la era digital, y es común estar conectados las 24 horas del día a canales de información y recibir notificaciones constantes en nuestros teléfonos de los principales medios de prensa o televisión. Muchos cuentan con aplicaciones en sus teléfonos móviles que emiten alarmas específicas ante terremotos, tsunamis, y otros eventos naturales. Del mismo modo, podemos enteramos en tiempo real de cada caso positivo por COVID-19 y saber cómo las cifras de muertes han ido aumentando o disminuyendo a nivel local e internacional. Todo esto fortalece y propaga la infodemia, empeorando las ya terribles condiciones de la pandemia. Además, dificulta las tomas de decisiones para el personal de salud, que batalla para encontrar fuentes fidedignas cuando las necesitan, o cuando esperan respuestas inmediatas y no se asignó un tiempo suficiente para analizar los datos. Al no haber ningún control de calidad en cuanto a lo que se publica y tomando en cuenta que cualquiera puede publicar algo en internet, el problema se agrava y las personas pueden sufrir ansiedad, depresión, agobio, agotamiento emocional e incapacidad de satisfacer necesidades (OPS, 2020).

Otra consecuencia del mal uso de información durante etapas de crisis como la que vivimos actualmente, es el oportunismo. La Comisión Federal de Comunicaciones (FCC, por sus siglas en inglés, 2020) ha recibido múltiples denuncias de estafas generadas por mensajes de texto y llamadas fraudulentas, donde personas malintencionadas ofrecen kits de pruebas 
gratuitas, curas falsas y seguros de vida, entre otros. Un mecanismo habitual del engaño es atribuir autoridad a una persona que habla de un asunto en el que no se especializa; esta "autoridad ampliada" se apoya en el desconocimiento científico de las personas, y los estafadores y mentirosos manejan hábilmente este principio (Salaverría et al., 2020). Ante este problema, la Organización Mundial de la Salud emitió una advertencia sobre delincuentes que tratan de sacar provecho de esta pandemia para robar dinero o información y exhortan a no fiarse de estas llamadas (FCC, 2020). Ante la peligrosidad de los desórdenes de información, resulta determinante el comportamiento de los sujetos en su interacción con la información, ya que la problemática aumenta considerablemente cuando surgen hechos que por su significancia se tornan globales. Se deben evaluar las competencias informacionales de la persona para evaluar con pensamiento crítico toda fuente y canal de información (Alfonso \& Fernández, 2020).

\section{Recomendaciones para Combatir los Desórdenes de Información durante la Pandemia por COVID-19}

Las personas necesitan tener la sensación de que viven en un ambiente seguro y controlado. La inseguridad y la incertidumbre vinculadas con la pandemia, facilitan la aparición de conductas dañinas (Gallegos, et al., 2020). Es por esto que las personas deben saber lo que está sucediendo, el por qué y cuánto tiempo continuará; los funcionarios de gobierno y de salud deben asegurar la provisión de suministros básicos como alimento, agua y medicamentos, proveer alternativas de actividades a realizar en cuarentena, así como una comunicación clara (Brooks et al., 2020). Poner fin a los desórdenes de información es imperioso. En un mundo globalizado, donde el desconocimiento es arma de manipulación y engaños, el conocimiento juega un papel de antídoto ante la ignorancia (Alfonso \& Fernández, 2020). Atacar la obesidad informativa con la práctica de dietas digitales es la propuesta de Romero y Aguaded (2016). Esta dieta incluye enfocarse en la cantidad de información consumida, la capacidad de análisis crítico de los mensajes recibidos, la eliminación de conductas multitareas que tienden a la distracción y el reentrenamiento para interactuar en las redes sociales. Proponen además la educomunicación como medida formativa de seres responsables ante el uso de los medios digitales. Alfonso Sánchez, directora del Centro Nacional de
Información de Ciencias Médicas de Cuba, exhorta al sentido común y crítico ante la exposición de información. Recomienda hacer un análisis, empezando por al autor, seguido del contexto, la fuente, fecha de publicación, actualidad, editorial y por último revisar las citas falsas (Ortega, 2020). El sentido del humor puede tener efectos positivos que ayudan a mitigar la intensidad de las reacciones ante situaciones estresantes (Garrik, 2006), por lo que es preferible compartir memes y chistes que desdramaticen la situación, siempre tomando en cuenta no descalificar o herir susceptibilidades (Gallegos et al., 2020).

Ante el incremento de información desestructurada que se comparte desproporcionadamente sin evaluación previa, cada persona tiene la responsabilidad individual de evaluar antes de reutilizar y diseminar información (Alfonso \& Fernández, 2020). No olvidemos que, para poder ser llamados expertos en cualquier campo, debemos haber dedicado todas las horas de trabajo y lectura necesarias, desde el comienzo de la carrera hasta el retiro (Fraser \& Dunstan, 2010). Area-Moreira y Pessoa (2012), proponen la creación de un modelo de alfabetización integrado para la formación del ciudadano en la sociedad digital. Explica que un sujeto alfabetizado en cultura digital debe tener habilidades y competencias instrumentales, cognitivas-intelectuales, socioculturales, axiológicas y emocionales. La alfabetización digital logrará formar individuos cultos, responsables y críticos, a través del conocimiento promotor de libertad individual y democracia. Por otra parte, no debemos olvidar que el acceso a la información a través de internet o un teléfono inteligente no es privilegio de todos y hay muchos que carecen de los mismos. Por ende, se debe asegurar que las poblaciones vulnerables, minorías y desaventajados sean provistos de información de primera necesidad, principalmente en materia de salud y prevención (Gallegos et al., 2020).

\section{Presentación del Volumen 4, Número 2}

Las implicaciones de la infodemia en la actual pandemia por COVID-19, nos llevan a la reflexión, por lo que se sugiere leer el presente número de la Revista Caribeña de Psicología con un buen café a la mano. Este incluye una sección especial dedicada al tema del COVID-19. Se exponen una variedad de temas noveles que reflexionan en asuntos puntuales de la profesión de la psicología y la salud mental. 
Específicamente, el primer artículo de la sección especial trata el asunto de la pandemia y sus implicaciones psicológicas. Este trabajo concluye que algunos trastornos psiquiátricos han aumentado considerablemente, en especial la ansiedad, la depresión y el insomnio.

Por su parte, reconocidísimos colegas cubanos trabajaron una revisión narrativa donde abordaron temas relacionados a traumas, factores estresantes, infodemia, programas de salud, desastres y el rol protagónico de la comunidad y el Gobierno en brindar ayuda psicosocial. Además, una colega boricua analiza la evaluación psicológica de forma remota y sus implicaciones éticas, sus modalidades y el debido proceso de administración. Culmina su escrito ofreciendo algunas recomendaciones de cómo se podría utilizar la evaluación remota en el futuro. Esta sección especial finaliza con un estudio que examina las demandas tecnológicas y psicológicas que experimentaron estudiantes universitarios de Puerto Rico tras el cambio en el modo de educación presencial a remota, debido a la pandemia.

La sección de artículos originales contiene cuatro artículos muy interesantes. El primero tuvo como

\section{REFERENCIAS}

Alfonso, I., \& Fernández, M. (2020). Comportamiento informacional, infodemia y desinformación durante la pandemia de COVID-1. Anales de la Academia de Ciencias de Cuba, 10(2), e882. http://www.revistaccuba.cu/index.php/revacc/article/view/882/889

Area-Moreira, M., \& Pessoa, T. (2012). De lo sólido a lo líquido: Las nuevas alfabetizaciones ante los cambios culturales de la Web 2.0. Comunicar, 38(1), 13-20. https://doi.org/10.3916/C38-201202-01

Baquero, L., Gil, C., \& Hernández, M. (2017). Modelo de desinfoxicación para el proceso de enseñanza-aprendizaje. Revista Redes de Ingeniería, 8(2), 101-109. https://doi.org/10.14483/2248762X.11760

Benito-Ruiz, E. (2009). Infoxication 2.0. In Thomas, M. (Eds.), Handbook of Research on Web 2.0 and Second Language Learning (pp. 6079). IGI Global. http://doi:10.4018/978-1-60566-190-2.ch004

Brooks, S. K., Webster, R. K., Smith, L. E., Woodland, L., Wessely, S., Greenberg, N., \& James, G. (2020). The psychological impact of quarantine and how to reduce it: Rapid review of the evidence. The Lancet, 395(10227), 912-920. https://doi.org/10.1016/S0140-6736(20)30460-8

Centers for Disease Control and Prevention. (2020). Quarantine and isolation. Coronavirus disease 2019 (COVID-19). https://www.cdc.gov/coronavirus/2019-ncov/if-you-aresick/quarantine-isolation.html propósito desarrollar un perfil cognitivo y psicológico de monjas católicas residentes de Puerto Rico. El segundo estudio trata sobre la extinción del miedo condicionado y aspectos neuropsicológicos y psicológicos del Trastorno Obsesivo Compulsivo en adultos puertorriqueños. El tercero es de carácter psicométrico y trata sobre el desarrollo de una escala de interés en animales. Esta sección finaliza con un magistral estudio que examina los fracasos repetidos en los exámenes de reválida, de profesionales en transición. Este número culmina con una extensa revisión de literatura en un tema de escasa exploración científica en Puerto Rico, estudios sobre hombres gay.

\section{Novedades de la Revista}

Gracias al incremento de manuscritos recibidos, la revista empezará a publicarse tres veces al año (enero-abril, mayo-agosto y septiembre-diciembre). Esto se traduce en que la revista tendrá convocatoria abierta todo el año para recibir manuscritos. Recordamos que los artículos deben someterse en formato Word y en estilo APA 7ma edición. Todo artículo debe ser sometido a través de nuestra página web. Les invitamos a seguir patrocinando la revista, tanto a los lectores asiduos como a los autores.

Culiford, E. (2020). Twitter launches labels, warnings on misleading COVID-19 information. Reuters. Technology News. https://www.reuters.com/article/us-health-coronavirus-twitter/twitter-launches-labels-warnings-on-misleading-covid-19information-iduskbn22n2e4

Federal Communications Comission [FCC]. (2020). Advertencias y consejos de seguridad para consumidores. Consumer and governmental affairs. https://www.fcc.gov/covid19-scams-espanol

Fischer, S., \& Fried, I. (2020). Misinformation about coronavirus is spreading fast. AXIOS. https://www.axios.com/coronavirus-misinformation-facebook-twitter-google-china246a0325-b4ea4465-92ae-5f364a7e965c.html

Fraser, A. G., \& Dunstan, F. D. (2010). On the impossibility of being expert. BMJ, 341, c6815. https://doi.org/10.1136/bmj.c6815

Gallegos, M., Zalaquett, C., Luna-Sánchez, S. E., Mazo-Zea, R., Ortiz-Torres, B., Penagos-Corzo, J. C., Portillo, N., Torres Fernández, I., Ursúa, A., Morgan Consoli, M., Polanco, F. A., Florez, A. M., \& Lopes Miranda, R. (2020). Cómo afrontar la pandemia del Coronavirus (Covid-19) en las Américas: recomendaciones y líneas de acción sobre salud mental. Revista Interamericana De Psicología, 54(1), e1304. https://doi.org/10.30849/ripijp.v54i1.1304

Garrick, Jacqueline. (2006). The Humor of Trauma Survivors. Journal of Aggression, Maltreatment \& Trauma, 12(1-2), 169-182. https://doi.org/10.1300/J146v12n01_09 
Ireton, C., \& Posetti, J. (2018). Journalism, 'fake news' $\mathcal{E}$ disinformation: Handbook for journalism education and training. United Nations Educational, Scientific and Cultural Organization. https:/en.unesco.org/sites/default/files/journalism_fake_news_disinformation_print_friendly_0.pdf

Khantzian, E. (1997). The self-medication hypothesis of substance use disorders: A reconsideration and recent applications. Harvard Review of Psychiatry, 4(5), 231-44. https://doi.org/10.3109/10673229709030550

López-Cañón, L. M., \& Pérez-Acosta, A. M. (2020). Covid-19, automedicación y cuarentena. SIP Bulletin. Número Especial Covid-19. https://sipsych.org/publications/sip-bulletin/

Lorenzo-Ruiz, A., Díaz, K., \& Zaldívar, D. (2020). La psicología como ciencia y profesión en el afrontamiento del COVID-19. Revista Caribeña de Psicología, 4(2), 153-165. https://doi.org/10.37226/rcp.v4i2.4815

McCartney, M. (2020). Medicine: Before COVID-19, and after. The Lancet, 395(10232), 1248-1249. https://doi.org/10.1016/s01406736(20)30756-x

Organización Panamericana de la Salud [OPS]. (2020). Entender la infodemia y la desinformación en la lucha contra la COVID-19. https://www.paho.org/es/documentos/entender-infodemiadesinformacion-lucha-contra-covid-19

Ortega, Y. (2020). La desinformación y el coronavirus ¿Cómo hacer frente a la infodemia? Portal Infomed. [Internet]. Cuba: Centro Nacional de Información de Ciencias Médicas. http://www.sld.cu/noticia/2020/04/15/la-desinformacion-y-elcoronavirus-como-hacer-frente-la-infodemia

Posetti, J., \& Bontcheva, K. (2020). Disinfodemic: Deciphering COVID19 disinformation. United Nations Educational, Scientific and Cultural Organization. https://en.unesco.org/covid19/disinfodemic/brief1

Romero, L. M., \& Aguaded, I. (2016). Consumo informativo y competencias digitales de estudiantes de periodismo de Colombia, Perú y Venezuela. Convergencia, 23(70), 35-57. https://doi.org/10.29101/crcs.v23i70.3806

Salaverría, R., Buslón, N., López-Pan, F., León, B., López-Goñi, I., \& Erviti, M. C. (2020). Desinformación en tiempos de pandemia: Tipología de los bulos sobre la Covid-19. Profesional de la Información, 29(3, e290315. https://doi.org/10.3145/epi.2020.may.15

Zarocostas J. (2020). How to fight an infodemic. Lancet, 395(10225), 676. https://doi.org/10.1016/S0140-6736(20)30461-X

\section{Obra bajo licencia de Creative Commons Atribución 4.0 Internacional (CC BY 4.0).} (C) 2020 Autores. 